\title{
Lingüística
}

Vol. 36-2, diciembre 2020: 89-106

ISSN 2079-312X en línea

DOI: $10.5935 / 2079-312 X .20200016$

\section{O PROCESSAMENTO DOS CLÍtICOS TE E LHE NO PORTUGUÊS BRASILEIRO: A CONTRAPARTE COGNITIVA DA VARIAÇÃO}

\author{
PROCESAMIENTO DE LOS CLÍTICOS TE Y LHE EN EL PORTUGUÉS BRASILEÑO: \\ LA CONTRAPARTE COGNITIVA DE LA VARIACIÓN
}

THE PROCESSING OF CLITICS TE AND LHE IN BRAZILIAN PORTUGUESE: THE COGNITIVE COUNTERPART OF THE VARIATION

Thiago Laurentino de Oliveira Universidade Federal do Rio de Janeiro thiago.laurentinodeoliveira@gmail.com

0000-0002-9537-5264

\section{Resumo}

Neste artigo, analisamos, a partir da metodologia experimental, a variação entre os clíticos te e Ihe na função de objeto direto. Alguns estudos afirmam que Ihe, originalmente um clítico dativo de $3 \mathrm{SG}$, é reinterpretado no Português Brasileiro como um acusativo de 2SG, p. ex.: "Eu Ihe vi", após a difusão da forma você no sistema pronominal (Ramos 1999; Almeida 2009; Souza 2014). Desse modo, Ihe passa a variar com te no contexto sintático acusativo. Para analisar a contraparte cognitiva dessa variação, elaboramos um teste de leitura automonitorada (self-paced reading), aplicado a participantes nativos de dois estados brasileiros (Rio de Janeiro e Ceará). No experimento, testamos algumas hipóteses recorrentes na literatura sobre o tema: (i) a ambiguidade referencial do clítico the e (ii) o condicionamento diatópico acerca do uso de Ihe.

Palavras-chave: Variação linguística; Abordagem experimental; Pronomes pessoais.

\section{Resumen}

En este artículo se analiza, desde la metodología experimental, la variación entre los clíticos te e Ihe en función de objeto directo. Algunos estudios afirman que, originalmente un clítico dativo de $35 \mathrm{SG}$, se reinterpreta en portugués brasileño como un acusativo de 2SG, p. ej.: "Eu Ihe vi", luego de la difusión de la forma você en el sistema pronominal (Ramos 1999; Almeida 2009; Souza 2014). 
De esta manera, Ihe comienza a variar con te en el contexto sintáctico acusativo. Para analizar la contraparte cognitiva de esta variación, desarrollamos una prueba de lectura autocontrolada, aplicada a participantes nativos de dos estados brasileños (Río de Janeiro y Ceará). En el experimento, probamos algunas hipótesis recurrentes en la literatura sobre el tema: (i) la ambigüedad referencial del clítico Ihe y (ii) el condicionamiento diatópico sobre el uso de /he.

Palabras clave: Variación lingüística; Enfoque experimental; Pronombres personales.

\begin{abstract}
In this paper, I analyze, from the experimental methodology, the variation between te and Ihe clitics as direct object. Some studies claim that Ihe, originally a dative clitics of 3SG, is reinterpreted in Brazilian Portuguese as an accusative of 2SG, e.g.: "Eu lhe vi" after expansion of você form in the pronominal system (Ramos 1999; Almeida 2009; Souza 2014).

Thus, Ihe vary with te at accusative context. To analyze the cognitive counterpart of this variation, I developed a self-paced reading test, applied to participants of two Brazilian States (Rio de Janeiro and Ceará). In the experiment, I tested some recurrent assumptions in literature about the topic: (i) the referential ambiguity of clitics /he and (ii) the diatopic conditioning about the use of the.
\end{abstract}

Keywords: Linguistic variation; Experimental approach; Personal pronouns.

Recebido: $28 / 01 / 2019$

Aceito: 27/05/2019

\title{
1. Considerações iniciais
}

No âmbito da expressão pronominal de segunda pessoa do singular (2SG), chama a atenção dos linguistas, há tempos, a complexa realização variável existente nessa parte da gramática do Português Brasileiro ( $P B)$. Além de envolver um vasto conjunto de condicionadores linguísticos e sociais, esse fenômeno se destaca também pela quantidade de variantes que recruta. Estas se distribuem entre as funções sintáticas da sentença nas quais pode haver um pronome pessoal.

Dentre essas variantes, analisaremos, neste artigo, as formas clíticas te e Ihe, que podem ocorrer nas funções de objeto direto e objeto indireto no PB contemporâneo. A variação linguística envolvendo essas formas tem sido objeto de diferentes estudos. O ponto de partida para a exploração do tema é, quase sempre, diacrônico, uma vez que a origem desse fenômeno está relacionada ao processo de mudança linguística por que tem passado o quadro 
de pronomes pessoais do PB nos últimos séculos, sobretudo após a emergência e difusão da forma gramaticalizada você (Lopes et al. 2018).

$\mathrm{Na}$ tentativa de mapear a dinâmica desse fenômeno de variação, trabalhos baseados em corpora têm revelado que, mesmo após a difusão de você no quadro pronominal, a forma te ainda figura como uma variante bastante produtiva. Brito (2001) propõe como hipótese a questão da ambiguidade referencial: o clítico Ihe, teoricamente, também pode se referir à 3SG. Além disso, Ihe não possuiria o traço semântico de [2SG], de modo que a interpretação de 2SG dependeria da presença de outra forma antecedente com esse traço (o pronome você, por exemplo).

Paralelamente a essas discussões mais gramaticais, há ainda questões de ordem extralinguística importantes de serem tratadas. Dentre elas, destacamos a hipótese de que a variante lhe seria um marcador linguístico (Labov 1972), associado aos dialetos nordestinos (Ramos 1999). Os resultados de pesquisas recentes têm sustentado essa hipótese, registrando um uso considerável dessa variante na fala de indivíduos nativos de localidades nordestinas (Araújo e Carvalho 2015; Almeida 2016).

Diante desses pontos, buscamos contribuir com o tema trazendo para a discussão aspectos relativos ao processamento linguístico de te e the por falantes do PB. Pretendemos, neste estudo, (i) mensurar o custo de processamento exigido pelas formas te e the para a ativação da referência à 2SG e (ii) observar se o fator diatópico exerce influência no processamento das variantes em análise. Para a concretização desses objetivos, adotamos a metodologia experimental da leitura automonitorada (self-paced reading), uma técnica on-line bastante conhecida e utilizada na psicolinguística. 0 experimento foi aplicado a falantes nativos do PB, oriundos dos estados do Rio de Janeiro e Ceará.

Organizamos este artigo da seguinte maneira: após esta introdução, fazemos uma breve revisão dos estudos acerca dos clíticos te e /he na seção 2; delineamos, na seção 3 , a técnica experimental escolhida como metodologia alternativa para análise; apresentamos e discutimos os resultados experimentais obtidos na seção 4; em 5, por fim, tecemos as considerações finais acerca deste trabalho.

\section{Os clíticos te e lhe como acusativos de 2SG no PB}

Nesta seção, apresentamos três aspectos concernentes ao uso dos clíticos te e the como objeto direto (acusativo) de 2SG no PB. Primeiramente, revisamos alguns trabalhos descritivos, de cunho histórico, que tratam das origens das variantes e dos processos de mudança linguística que as afetaram. Em seguida, comentamos os resultados gerais e mais significativos de pesquisas sociolinguísticas recentes sobre a variação entre te e the em dados de corpora.

Por fim, discutimos a hipótese diatópica levantada por alguns linguistas de que o clítico the - como acusativo de 2SG - seria um marcador linguístico no $\mathrm{PB}$, associado aos falares nordestinos. 


\subsection{O percurso histórico das variantes}

A variação entre as formas te e the no PB atual decorre de um processo mais amplo, ocorrido no sistema de tratamento do português, em que se verifica a associação de paradigmas pronominais distintos. Faria (1958) afirma que, no latim, os pronomes pessoais apresentavam flexões morfológicas para marcar o caso (nominativo, acusativo, dativo etc.) que a forma recebia na oração. A forma $T \bar{u}$, que indicava referência ao interlocutor (2SG), flexionavase em tēe, quando exprimia o acusativo (objeto direto), e em tibì, quando exprimia o dativo (objeto indireto).

Os ditos pronomes pessoais "do caso reto" do português vieram, segundo o autor, das antigas formas latinas de nominativo (por ex., tu); já os pronomes pessoais átonos "do caso oblíquo" (me, te, nos, se) são oriundos das formas acusativas latinas. Das flexões dativas (mihi, tibi, sibi), surgiu a série de "pronomes oblíquos tônicos" ( $\mathrm{mim}$, ti, si), que, em português, são obrigatoriamente encabeçados por preposição. Além disso, a língua portuguesa também herdou do latim a distinção tu (nominativo-sujeito) e te (acusativo/dativo-objeto). Esse resquício do sistema de casos morfológicos latinos sobrevive até hoje e, em grande parte da história do português, o emprego de te esteve associado ao paradigma de tu.

Apesar dessas correspondências, há diferenças importantes entre os sistemas pronominais latino e português. Câmara Jr. (1985: 96) destaca que o quadro pronominal português está "muito longe do sistema de casos latinos, em que o caso dependia da função do nome ou do pronome na frase". Williams (1994: 148) também chama a atenção para o fato de que o quadro pronominal do português não deve ser visto como uma cópia fiel dos pronomes latinos, "já que algumas formas de acusativo são usadas como dativo e algumas de nominativo e dativo são usadas como objeto de preposições".

Os autores ressaltam que as formas homônimas de acusativo e dativo existentes atualmente no português derivam de tē, a forma latina do acusativo: "Me, te, se (...) são reflexos do acusativo-ablativo $m \bar{e}, t \bar{e}$, sē. Mas em português os clíticos adverbais indicam o objeto direto ou indireto, isto é, equivalem a um acusativo-dativo (...)" (Câmara Jr. 1985: 97); "Essas formas eram do acusativo em latim clássico, mas vieram a ser usadas como dativo e acusativo em português" (Williams 1994: 154).

A forma Ihe inexistia no latim. Segundo Câmara Jr. (1985), esse pronome surge a partir do demonstrativo ille ("aquele") flexionado no caso dativo, illi. Quando passa a funcionar como um pronome pessoal, Ihe preserva essa marca casual, opondo-se à forma o/a, específica para o caso acusativo.

Tempos mais tarde, a gramaticalização e difusão de você (< Vossa Mercê) no sistema de tratamento do português criou a possibilidade de que certas formas pronominais de 3SG - como o pronome lhe - passassem a atuar na referência à 2SG.

Isso porque Vossa Mercê era, originalmente, uma construção nominal. Assim, certos pronomes de 3SG foram reinterpretados, em correlação com você, e inseridos no âmbito da 2SG. Com isso, o quadro pronominal sofre um rearranjo quanto ao inventário de pronomes pessoais. 
Todavia, a implementação de você no sistema, juntamente com a migração de formas pronominais de 3SG para 2SG, não implicou no desaparecimento do pronome tu e suas formas correlatas (te, teu, contigo etc.).

Devido a isso, temos, no PB atual, um complexo fenômeno de variação linguística envolvendo a representação da 2SG (cf. Lopes et al. 2018). No que se refere às formas te e Ihe em função de objeto direto, tema central deste artigo, surge a pergunta: como se dá a variação entre elas nas variedades do $\mathrm{PB}$ ?

\subsection{A alternância das variantes em dados de corpora}

Souza (2014) explora, em sua dissertação, a variação na expressão de 2SG em posição de complemento na variedade fluminense. A autora mapeou todas as variantes de 2SG na função de acusativo/objeto direto levantadas em um corpus de 504 cartas pessoais escritas entre as décadas de 1880 e 1980.

De um total de 433 dados, ela contabilizou 337 ocorrências de te $(77,8 \%), 40$ de o/a $(9,2 \%), 29$ de você $(6,7 \%), 17$ de lhe $(4 \%)$ e 10 de objeto nulo $(2,3 \%)$. Esse resultado destaca, dentre outras coisas, a força da variante te na variedade do Rio de Janeiro frente a um uso reduzido da variante /he.

Focalizando especificamente as variantes te e Ihe, distribuímos, no Gráfico 1 , as ocorrências dessas formas na diacronia analisada por Souza (2014):

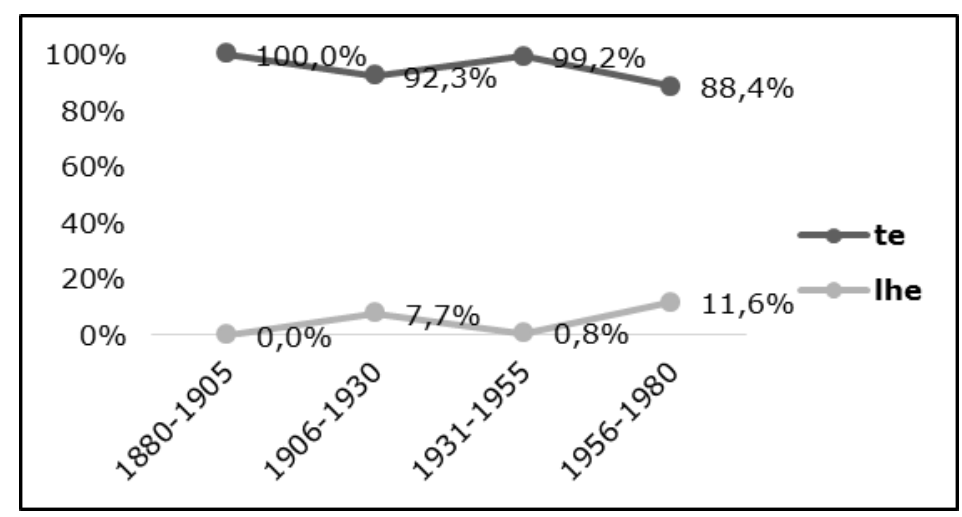

Gráfico 1: Distribuição diacrônica dos clíticos te e Ihe na escrita epistolar fluminense (adaptado de Souza 2014)

Podemos observar facilmente que a variante te prevalece nos quatro recortes temporais estudados - 44 ocorrências entre 1880-1905, 132 entre 1906-1930, 123 entre 1931-1955, e 38 entre 1956-1980 -, com uma diferença bastante acentuada em relação aos índices de lhe nos mesmos recortes (nenhum dado entre 1880-1905, 11 dados entre 1906-1930, 1 ocorrência entre 1931-1955, e 5 entre 1956-1980).

As linhas do gráfico sugerem, pois, certa estabilidade na frequência de uso dessas variantes clíticas na documentação epistolar produzida ao longo de cem anos.

Ainda em relação à ocorrência da variante Ihe nas cartas, Souza (2014) afirma que o uso dessa variante está relacionado com a variável subgênero da carta. 
Na composição da amostra, havia missivas de natureza diversa amorosas, familiares e pessoais (não-familiares); dentre eles, a pesquisadora constatou que o subgênero carta pessoal (no qual havia menor grau de intimidade entre os interlocutores) favorecia fortemente as ocorrências de Ihe, que, segundo a autora, "assume um caráter [+formal] nesse tipo de missiva." (Souza 2014: 146).

O estudo de Camargo Jr. (2007) explorou a posição de complemento verbal acusativo de 2SG na variedade paulista. Como corpus, o autor utilizou produções textuais de estudantes do segundo segmento do ensino fundamental de um colégio particular da cidade de São Paulo. Os alunos foram solicitados a redigir uma carta, o que, naturalmente, propiciou a ocorrência de objetos diretos de 2SG. A tarefa foi dividida em duas modalidades - formal e informal.

Ao todo, Camargo Jr. (2007) contabilizou 1.524 dados de objeto direto de 2SG, sendo 595 deles produzidos na modalidade formal (39\%) e 929, na modalidade informal (61\%). Quanto às estratégias utilizadas, houve a ocorrência de clíticos, pronomes tônicos, sintagmas nominais e de objeto nulo. As formas clíticas foram majoritárias no corpus, correspondendo a 1019 dados (66,9\% da amostra). Apresentamos, na Tabela 1, apenas os percentuais das variantes te e /he, reportados pelo autor:

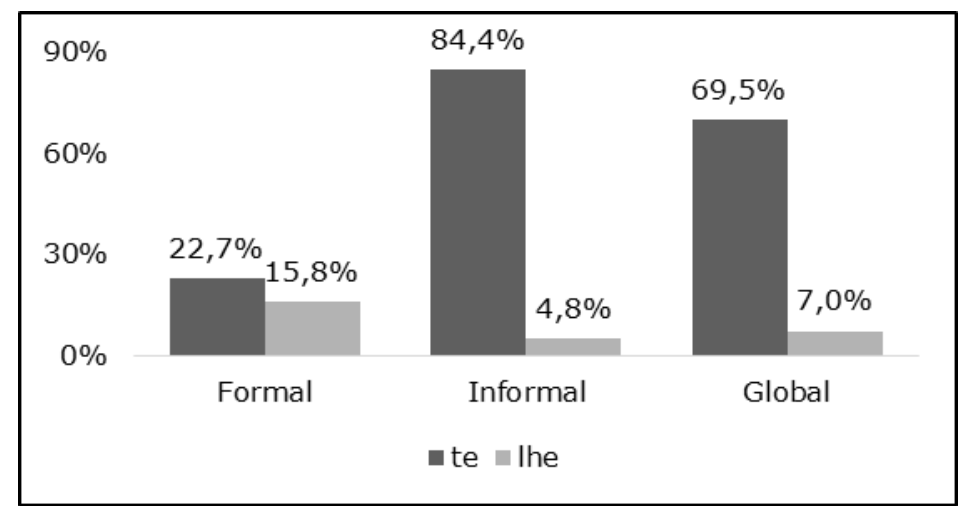

Tabela 1: A produtividade dos clíticos te e Ihe em função acusativa na redação de estudantes paulistanos (adaptado de Camargo Jr. 2007: 130)

As barras percentuais ilustram que o pronome te foi a variante mais produzida pelos estudantes, com um percentual global próximo a 70\% (708 dados, sendo 56 destes na modalidade formal e 652 na modalidade informal). Já o clítico Ihe obteve uma frequência bem mais reduzida, correspondendo a $7 \%$ das formas clíticas produzidas pelos alunos. No contexto formal, essa variante teve um percentual de 15,8\% (39 dados), $11 \%$ a mais do que foi verificado para o contexto informal $(4,8 \%)$. Essa diferença vai ao encontro da hipótese levantada por Souza (2014) de que o clítico lhe exprime marca de formalidade.

Com base na variedade cearense, Araújo e Carvalho (2015) também abordam a variação entre te e Ihe na função de objeto direto. Assim como Souza (2014), os pesquisadores também examinam uma amostra de cartas pessoais, composta por 186 documentos produzidos entre 1940 e 1990 . Nesse corpus, os autores encontraram 149 ocorrências de clíticos de 2SG, sendo 90 dados do pronome te $(60 \%)$ e 59 do pronome lhe $(40 \%)$. 
Ao analisarem a distribuição dos dados ao longo do período investigado, Araújo e Carvalho (2015) verificaram que the é predominante nas cartas escritas entre 1940 e 1950 (56\%, 09/16 oco.), em comparação com as ocorrências de te (44\%, 07/16 oco.); já entre as décadas de 1960 e 1970, o cenário se inverte em favor de te ( $54 \%, 34 / 63$ oco.), que se sobrepõe ao índice de Ihe (46\%, 29/63 oco.); entre as décadas de 1980 e 1990, a distância entre os percentuais de the e te acentua-se, com 70\% (49/70 oco.) de frequência para este, frente a $30 \%$ (21/70 oco.) para aquele. Vejamos os referidos percentuais projetados no Gráfico 2:

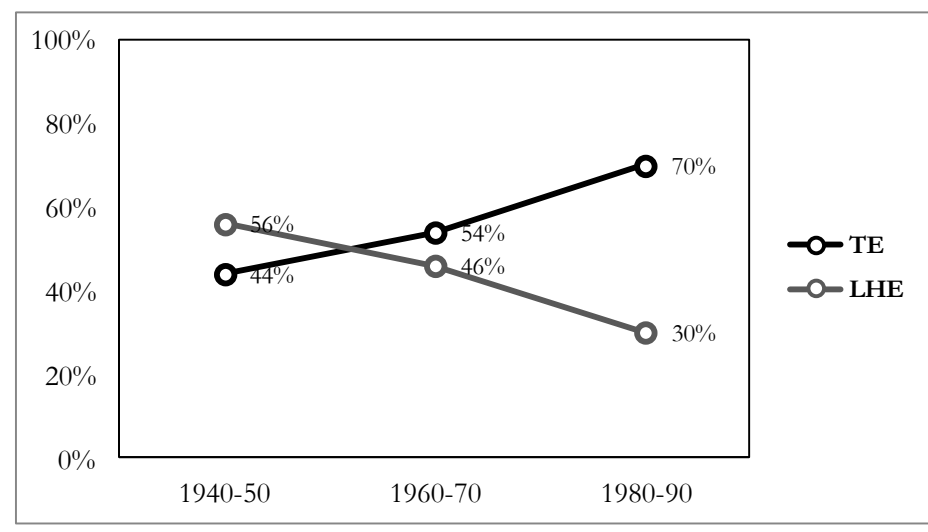

Gráfico 2: Distribuição diacrônica de te e lhe acusativos na escrita epistolar cearense (adaptado de Araújo e Carvalho 2015: 76)

O Gráfico 2 ilustra uma distribuição bastante interessante, pois vai de encontro à ideia de que the é a variante típica dos dialetos nordestinos. O índice de the nas cartas escritas entre 1980-1990 é superior àquele verificado, para o mesmo período, por Souza (2014), em cartas cariocas (pouco mais de $10 \%)$; entretanto, o gráfico sugere que a forma Ihe, na variedade cearense, está caindo em desuso, enquanto te parece se estabelecer como a variante majoritária para a função de acusativo.

Outro estudo que também explora a variação te/lhe no objeto direto é o de Almeida (2016). A pesquisadora investigou o uso dos pronomes acusativos de 2SG nas cidades de Salvador e Santo Antônio de Jesus (Bahia). Para tanto, a autora examinou amostras de fala de 24 informantes (12 de cada cidade), estratificados segundo o sexo, faixa etária e escolaridade.

A partir de questionários construídos para induzir à produção de formas pronominais de 2SG pelos informantes durante a entrevista, Almeida (2016) obteve 516 dados (218 dados em Salvador e 298 dados em Santo Antônio de Jesus). Das 218 ocorrências em Salvador, 91 foram do clítico Ihe (42\%) e 83, do clítico te $(38 \%)$. Já em Santo Antônio de Jesus, dos 298 dados coletados, houve 122 ocorrências de the (41\%) e 92 de te (31\%). Esses números revelam uma presença notável de Ihe na variedade baiana. Almeida (2016) correlacionou, ainda, a variável dependente com o fator extralinguístico faixa etária, o que forneceu outro dado interessante, conforme reproduzimos no Gráfico 3: 


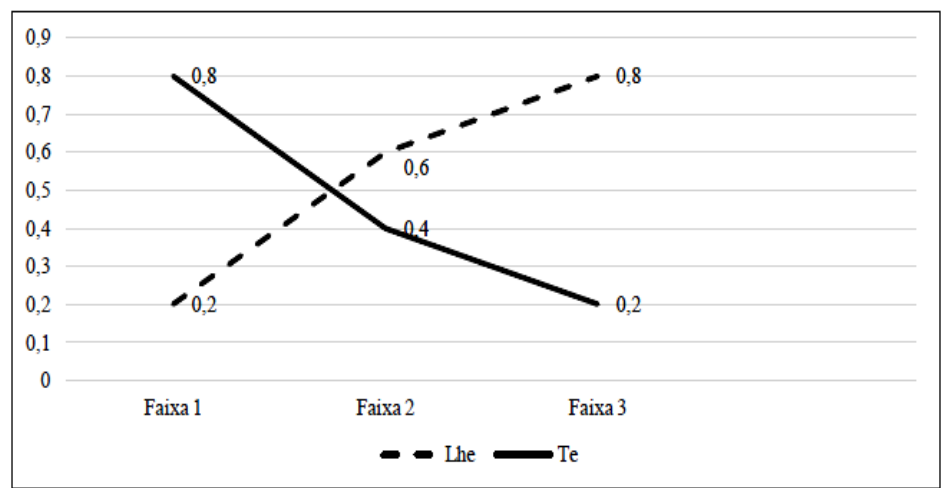

Gráfico 3: A atuação da variável faixa etária sobre os clíticos de 2SG em Salvador e Santo Antônio de Jesus (BA) (extraído de Almeida 2016: 130)

Lançando mão dos índices de peso relativo, Almeida (2016) afirma que os falantes mais idosos da amostra favorecem o uso de lhe (.800). Entre os indivíduos da faixa 2, esse favorecimento permanece, porém em menor índice (.600). Já os informantes mais jovens da amostra exibem um padrão oposto, visto que favorecem o uso da variante te (.800). Sob a ótica do modelo de tempo aparente (Labov 1994), poderíamos pensar em um processo de mudança em curso na variedade baiana, segundo o qual o pronome te estaria se generalizando na posição de objeto direto.

Com base nos resultados das quatro pesquisas mencionadas, vimos que (i) as formas te e the constituem, de fato, variantes pronominais de 2SG na função de objeto direto, ocorrendo em diferentes variedades do PB e (ii) a distribuição dessas variantes parece oscilar significativamente de uma região para outra, tendo Ihe uma frequência menos significativa em localidades da região sudeste (RJ e SP) do que em cidades da região nordeste (CE e BA).

Diante desse cenário, fica a questão: as diferenças observadas quanto à frequência da variante the estariam condicionadas à localidade de origem dos falantes do PB?

\subsection{O uso de Ihe como marcador linguístico: a hipótese diatópica}

Diversos estudiosos têm defendido que o uso expressivo do pronome the como forma acusativa de 2SG seria um caso de variação diatópica, uma vez que esse pronome estaria relacionado aos falares nordestinos. Almeida (2009: 18), por exemplo, ao discutir sobre o estatuto do clítico lhe no PB atual, salienta a produtividade desse pronome na referência à 2 SG e sua extensão para a função acusativa, destacando que "embora o fenômeno esteja presente em todo o Brasil (...), é em estados do Nordeste que ele se evidencia de maneira mais acentuada (...)".

A autora toma por base o trabalho de Ramos (1999), que analisou o emprego dos clíticos de 3SG le/lhe como objeto direto no Espanhol Peninsular e no PB. Ramos (1999) relaciona o uso de the na 2SG à perda da distinção entre os pronomes tu e você em diversas regiões do Brasil, o que permitiu que Ihe dativo de 3SG "invadisse" a função acusativa do pronome te. Diante do complexo quadro de reestruturação do sistema de tratamento, a pesquisadora postula a existência de três subsistemas no PB atual, tratados como três "gramáticas", segundo a perspectiva gerativa adotada por ela: 
(i) Gramática A: você é a expressão universal de tratamento; Ihe é a expressão de dativo de $2 \mathrm{SG}$ em relações de respeito/cortesia; te é a forma acusativa/dativa para o tratamento familiar/informal. Tal gramática corresponderia às variedades do eixo Rio-São Paulo.

(ii) Gramática B: você é a forma generalizada de tratamento; the substituiu te nas funções acusativa e dativa e, por essa razão, não se limita às situações de formalidade/respeito/cortesia, estendendo-se ao tratamento familiar/informal. Essa gramática representaria grande parte dos estados nordestinos, dentre os quais se destacam Maceió, Recife, Salvador e João Pessoa.

(iii) Gramática C: a distinção entre tu íntimo/familiar e você respeitoso/cortês se mantém; os usos de te e Ihe obedecem a mesma distinção, sendo te utilizado como clítico de tu e the como clítico de você, senhor/senhora, tanto no dativo quanto no acusativo. Tal gramática compreenderia a região Norte e o estado do Maranhão.

Tal proposta consiste mais em uma hipótese do que em um mapeamento empiricamente verificado. A própria autora alerta para esse fato, advertindo que será necessária uma pesquisa mais ampla sobre a questão, a fim de que se possam fazer afirmações mais concretas.

Com efeito, se voltarmos aos estudos comentados em 2.2, perceberemos algumas incongruências entre a proposta de Ramos (1999) e o que já foi atestado em dados de corpora. Primeiramente, vemos nos dados de Souza (2014) - que investigou a variedade do RJ - e de Camargo Jr. (2007) - que analisou a variedade de SP - a ocorrência, ainda que pequena, do clítico the na função de objeto direto (relacionada ao tratamento mais formal); esses dados relativizariam a projeção da "Gramática A", que não prevê o uso desse clítico como acusativo de 2SG.

Além disso, temos nos dados de Araújo e Carvalho (2015) e Almeida (2016) índices da forma te que invalidam a existência de uma "Gramática B" tal como fora postulada. Em vez de uma substituição completa de te por Ihe, os resultados das pesquisas ilustram um acirrado quadro de variação linguística, inclusive com uma tendência à "revitalização" de uso de te na variedade baiana atual (Almeida 2016).

Apesar disso, é preciso reconhecer que a associação entre o uso de the como objeto direto de $2 \mathrm{SG}$ e as variedades nordestinas encontra respaldo nos resultados das investigações sociolinguísticas. A diferença de uso dessa variante nos parece ser mais quantitativa do que qualitativa. É mais coerente afirmar que the de 2SG tem um uso mais expressivo nas localidades nordestinas, em contraste com outras localidades do Brasil, do que dizer que esse pronome é a única forma de 2SG na função acusativa nessas regiões.

Essa notável diferença quantitativa no uso de lhe, registrada entre diferentes localidades do Brasil, parece impactar a percepção dos falantes, que avaliariam essa variante, nos termos de Labov (1972), como um marcador sociolinguístico.

Embora sua utilização não gere estigma social sobre os usuários da variante, Ihe é condicionado por fatores estilísticos - como grau de formalidade 
- e sociais - como cidade de origem e faixa etária. Isso explica o fato de que diferentes estudiosos identifiquem o Nordeste como a área onde a realização de Ihe 2SG se dá com maior intensidade, sendo tratada como uma marca dialetal.

Conduzindo a discussão para o viés experimental, levantamos a seguinte questão: como os falantes de dois dialetos distintos (um que utilize expressivamente a forma the como 2SG e outro que não a utilize) processam os clíticos te e Ihe na função acusativa? Na tentativa de explorar essa questão, reportamos, a seguir, o projeto e os resultados de um experimento linguístico envolvendo essas variantes.

\section{Metodologia experimental}

$\mathrm{Na}$ presente seção, descrevemos o teste de leitura automonitorada elaborado por Oliveira (2018) e aplicado em dois estados brasileiros - Rio de Janeiro e Ceará. O intuito principal era verificar a eficiência dos clíticos te, Ihe e o/a para ativar a informação de 2SG na mente dos falantes. Embora o clítico o/a também tenha sido investigado por Oliveira (2018), nos restringiremos às análises dos clíticos te e Ihe, tendo em vista os propósitos deste artigo e as limitações desta exposição.

\subsection{Desenho do experimento}

A técnica da leitura automonitorada compreende a exibição de um enunciado dividido em partes menores (palavras, sintagmas ou mesmo sentenças completas). Os participantes leem os enunciados na tela do computador segundo uma rotina previamente estabelecida: para iniciar a tarefa, apertam uma tecla que traz à tela o primeiro segmento do enunciado; após a leitura deste, os sujeitos vão acionando repetidamente a mesma tecla para ler os demais segmentos, até que tenham lido o enunciado inteiro. Essa rotina justifica a identificação de "automonitorada" (ing. self-paced reading; Mitchell 2004; Garrod 2006), já que é o próprio participante que aciona o aparecimento dos estímulos na tela do computador.

Para o pesquisador, interessa analisar os intervalos de tempo entre a exibição de cada segmento, a partir do ritmo de acionamento da tecla de comando pelos participantes. A lógica da tarefa é que tempos de leitura maiores em segmentos específicos do texto podem indicar maior custo de processamento linguístico dos itens presentes nestes segmentos.

\subsection{Método}

A fim de testar a eficiência dos clíticos te e Ihe na ativação de um referente de $2 \mathrm{SG}$, foram criados itens experimentais que envolviam a menção de três nomes próprios dentro de uma estrutura de subordinação completiva com verbos dicendi. Nessa configuração, um dos nomes próprios admitia a interpretação de referente de 2SG. As frases experimentais apresentavam o seguinte formato: 
01. Sônia prometeu para Aldo na companhia de Davi: Eu te ajudo com a prova. PERgunTA: Sônia ajuda Davi com a prova?

Na oração matriz, com o verbo dicendi, aparecem os três nomes próprios. Além de introduzir referentes com traço [+pessoa], essa sentença forja uma situação dialógica, necessária para a inserção de pronomes de 2SG. Na oração completiva, aparecem dois pronomes pessoais: "eu", ligado ao sujeito da primeira sentença - em (01), [Sônia] -, e "te", vinculado ao constituinte da primeira sentença ([para Aldo], em (01)).

Depois de ler as sentenças com os nomes próprios e com o clítico, os participantes tinham de responder a uma pergunta relacionada com o clítico. No exemplo em (01), a resposta esperada seria "não", uma vez que o clítico te se refere a "Aldo". "Davi", nesse contexto, é um referente de 3SG, fora do eixo falante-ouvinte, que presencia a conversa entre "Sônia" e "Aldo".

Dentro desse formato, torna-se possível verificar se o clítico lhe gera ambiguidade referencial (Brito 2001). Em (02), temos o mesmo enunciado na versão com the:

02. Sônia prometeu para Aldo na companhia de Davi: Eu lhe ajudo com a prova. PERGUNTA: Sônia ajuda Davi com a prova?

Nesta versão, "Davi" pode ser interpretado como o referente de lhe, caso os participantes optem por uma interpretação de 3SG desse clítico. Essa possibilidade é vedada para te, que funciona somente como pronome de 2 SG. Dessa forma, é possível examinar, no experimento, qual leitura será atribuída a Ihe em contextos ambíguos.

\subsection{Participantes}

Participaram do experimento 60 sujeitos, sendo 30 naturais do Rio de Janeiro e 30 do Ceará. Destes, 24 eram do sexo masculino. Os participantes tinham, em média, 25 anos de idade. Todos possuíam nível superior (completo ou em andamento).

\subsection{Materiais}

Foram criados 30 enunciados experimentais, sendo 10 enunciados para cada tipo de clítico (te, Ihe e $o / a^{1}$ ). Os participantes foram organizados em 3 grupos distintos e cada grupo visualizava 10 itens experimentais mais 20 enunciados distratores. A divisão dos enunciados por grupos adotou a organização descrita em (03):

03.

Grupo 1: 5 enunciados com CLíTICO TE +5 enunciados com CLÍTICO LHE +20 distratores Grupo 2: 5 enunciados com CLÍTICO LHE +5 enunciados com CLíTICO O/A + 20 distratores Grupo 3: 5 enunciados com CLÍTICO TE +5 enunciados com CLÍTICO O/A + 20 distratores

\footnotetext{
${ }^{1}$ Conforme já esclarecemos anteriormente, não discutiremos os resultados relativos ao clítico o/a.
} 
Os enunciados distratores apresentavam a mesma estrutura sintática das frases experimentais, porém não continham nenhuma forma pronominal de 2SG. Quanto à distribuição dos itens experimentais, adotou-se o formato conhecido na abordagem experimental como within subjects ("dentre sujeitos"), segundo o qual todos os participantes são expostos a todas as condições experimentais. Cada grupo era formado por 20 participantes, sendo 10 nativos do Rio de Janeiro e 10 do Ceará. A inserção dos sujeitos nesses grupos foi aleatória.

Os enunciados experimentais e distratores foram inseridos no software PsychoPy v1.8 (Peirce 2009). Com essa ferramenta, foi possível programar a apresentação dos estímulos no computador e registrar as respostas e os tempos de leitura dos participantes. O PsychoPy também permitiu a randomização dos enunciados, de modo que cada participante lia as frases experimentais em sequências diferentes.

\subsection{Variáveis e condições}

No experimento em questão, foram controladas duas variáveis independentes: o tipo de clítico e o estado de origem. A primeira continha três níveis, enquanto a segunda apresentava dois níveis:

04.

(A) TIPO DE CLíTICO: te, Ihe ou o/a

(B) ESTADO DE ORIGEM: Rio de Janeiro e Ceará

O experimento lidou, portanto, com seis condições experimentais: te- $R J$, Ihe-RJ, o/a-RJ, te-CE, Ihe-CE e o/a-CE. Dessas, discutiremos aqui - vale frisar novamente - os resultados de quatro condições: te- $R J$, Ihe- $R J$, te-CE e Ihe-CE. No que tange às variáveis dependentes, obtiveram-se, a partir do teste de leitura automonitorada, duas medidas: a resposta das perguntas interpretativas e o tempo de leitura das frases:

05.

(a) RESPOSTA DAS PERGUNTAS INTERPRETATIVAS: $s i m$ ou não

(b) TEMPO DE LEITURA DAS FRASES: em milissegundos (ms)

\subsection{Procedimentos}

O experimento foi aplicado aos participantes em um "Macbook Pro, monitor de 15" (Apple, Macintosh). Cada sujeito recebia, individualmente, do pesquisador responsável, as orientações para realizar o teste. Todos os participantes cumpriam uma etapa de treino antes de iniciar o teste, na presença do pesquisador, a fim de receber orientações específicas e/ou de sanar dúvidas acerca da tarefa. Os sujeitos eram instruídos a manusear apenas a tecla "espaço" (para avançar para as telas seguintes) e, na tela da pergunta, as teclas "a" (para "sim") e "I" (para "não"). Essas teclas foram sinalizadas com um adesivo colorido.

Nas instruções, o pesquisador esclarecia a rotina do teste: clicando "espaço", apareceria um asterisco no centro da tela, o que indicaria a exibição de um novo enunciado na tela seguinte; clicando "espaço" novamente, surgiria 
a primeira frase, que deveria ser lida no menor tempo possível; acionando "espaço" pela terceira vez, apareceria a segunda frase, que também deveria ser lida o mais rápido possível; em mais um "espaço", surgiria uma pergunta relativa ao enunciado lido anteriormente. A pergunta só desapareceria da tela quando o participante clicasse em "a" ou "I", o que também deveria ser feito rapidamente. Respondida a pergunta, apareceria novamente um asterisco no centro da tela. Tal processo se repetiria até o fim, quando uma mensagem de agradecimento seria mostrada.

Após a etapa de treino, os participantes iniciavam o experimento propriamente dito. Durante a tarefa, os sujeitos ficavam sozinhos ou em um espaço suficientemente isolado no local de aplicação. Os participantes levaram, em média, 5 minutos para concluir a tarefa.

Os estímulos eram exibidos em meio escrito, de modo não-cumulativo, na cor preta, em fundo branco. Foi utilizada a fonte Times New Roman, tamanho 14, centralizado. Cada segmento do enunciado ocupava uma única linha. Quanto ao tamanho dos segmentos, a primeira sentença possuía 15 sílabas, a segunda sentença, 9 sílabas, e a pergunta interpretativa, 11 sílabas.

\subsection{Previsões}

Como previsões para o experimento, destacamos que:

(i) No que se refere à variável dependente respostas das perguntas interpretativas, podemos esperar que, se o pronome Ihe for, de fato, uma variante ambígua, que admite tanto a leitura de 2SG quanto a de 3SG, então os índices de respostas para a interpretação de 2SG desse clítico deverão ser significativamente menores do que os índices verificados para o clítico te, que nunca provoca ambiguidade;

(ii) Quanto à variável dependente tempo de leitura das frases, podemos prever um tempo de leitura significativamente maior para as frases relacionadas ao pronome Ihe, em comparação com o tempo de leitura das frases relacionadas a te, caso aquele pronome tenha uma interpretação ambígua, o que demandará maior esforço cognitivo e tempo de processamento durante a leitura dos enunciados pelos participantes;

(iii) Relacionando a hipótese diatópica à tarefa experimental em questão, podemos projetar que, se o clítico the funciona de maneira distinta na "gramática" dos falantes nordestinos e dos falantes da região sudeste (Ramos 1999), então os participantes cearenses - que utilizam frequentemente essa variante em seu vernáculo - deverão exibir uma performance diferenciada dos participantes fluminenses, isto é, os cearenses deverão optar, com frequência significativamente maior, pela leitura de 2SG de the e gastar um tempo significativamente menor para ler os enunciados com esse pronome.

\section{Resultados e análises}

\subsection{Resultados}


Organizamos a exposição dos resultados segundo as variáveis dependentes analisadas. Primeiramente, expomos os resultados relativos à resposta da pergunta interpretativa, traduzida no Gráfico 4 como "interpretação da informação de 2SG":

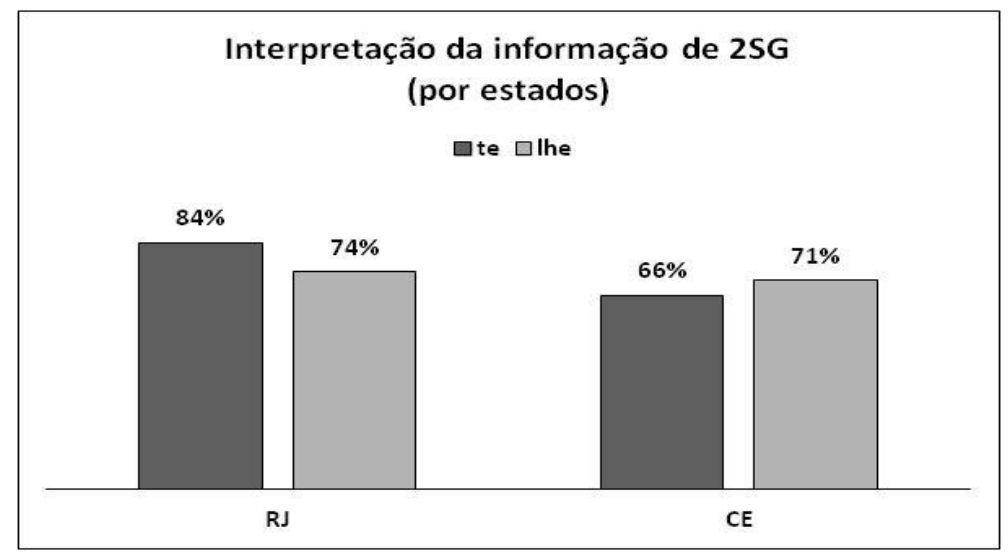

Gráfico 4: Interpretação da informação de 2SG segundo o tipo de pronome (em \%).

Verificamos, no Gráfico 4, que te favoreceu a interpretação de 2SG entre os participantes do RJ mais frequentemente (84\%) do que o clítico /he (74\%). Apesar da distância de $10 \%$ entre os índices de respostas, a aplicação do teste estatístico revelou que a diferença entre esses percentuais não é significativa $\left(\chi^{2}=2,44(1), p=0,11\right)$. Entre os participantes cearenses, a forma que mais propiciou a leitura de 2SG foi Ihe (71\%), em detrimento da forma te (66\%). Entretanto, essa diferença também não foi estatisticamente significativa $\left(\chi^{2}=0,37(1), p=0,54\right)$.

Confrontando os índices de interpretação da informação de 2SG segundo o tipo de clítico nos dois estados, observamos uma diferença percentual maior nas condições com te: $84 \%$ nas respostas dos participantes fluminenses frente a $66 \%$ nas respostas dos cearenses. Nas condições com lhe, os índices são bem próximos: $74 \%$ (RJ) e $71 \%$ (CE). Analisando esses percentuais estatisticamente, temos que as diferenças diatópicas não são significativas (te: $\chi^{2}=2,16(1), p=0,14$; lhe: $\left.\chi^{2}=0,06(1), p=0,80\right)$.

Prosseguindo com a análise, examinamos, no Gráfico 5 , os resultados relativos às médias de tempo de leitura da frase com o clítico:

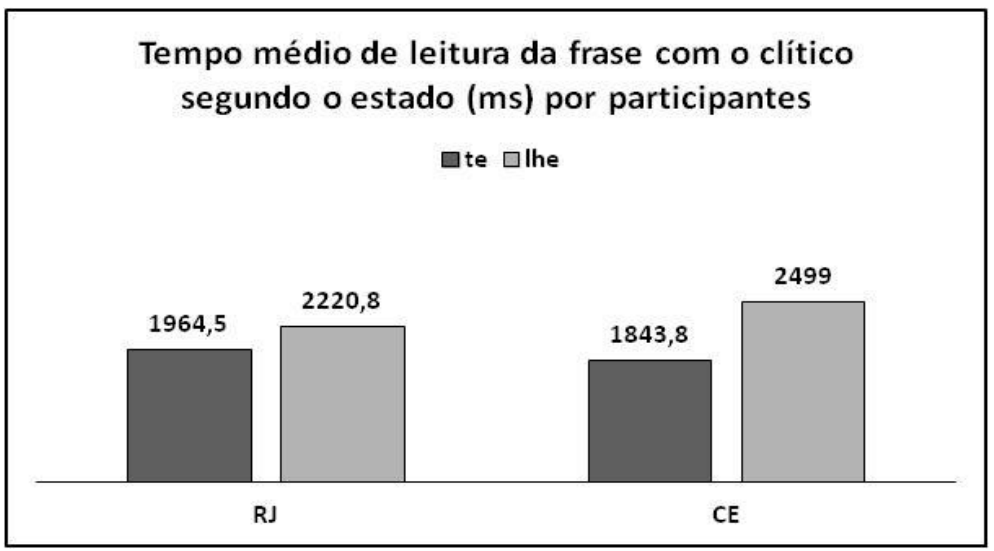

Gráfico 5: Média de tempo de leitura (ms) das frases com o clítico pelos participantes. 
Percebemos que tanto os participantes do RJ quanto os participantes do CE gastaram menos tempo para ler as frases que continham o clítico te: registrou-se um tempo médio de 1964,5 milissegundos para os primeiros e de 1843,8 milissegundos para os últimos. As frases que continham o clítico lhe contabilizaram médias maiores, sendo 2220,8 milissegundos entre os participantes do RJ e 2499 milissegundos entre os participantes do CE. A análise estatística indicou que a média de leitura para as frases com te foi significativamente menor em relação à média da frase com lhe nos dados do Ceará $(\mathrm{t}(19)=3,82 p<0,01)$; o mesmo não se verifica para a diferença entre as médias de tempo dos participantes do Rio de Janeiro (t (19) $=1,52 p=$ $0,14)$.

Dando continuidade à apresentação dos resultados, passamos então às médias de tempo de leitura da pergunta interpretativa:

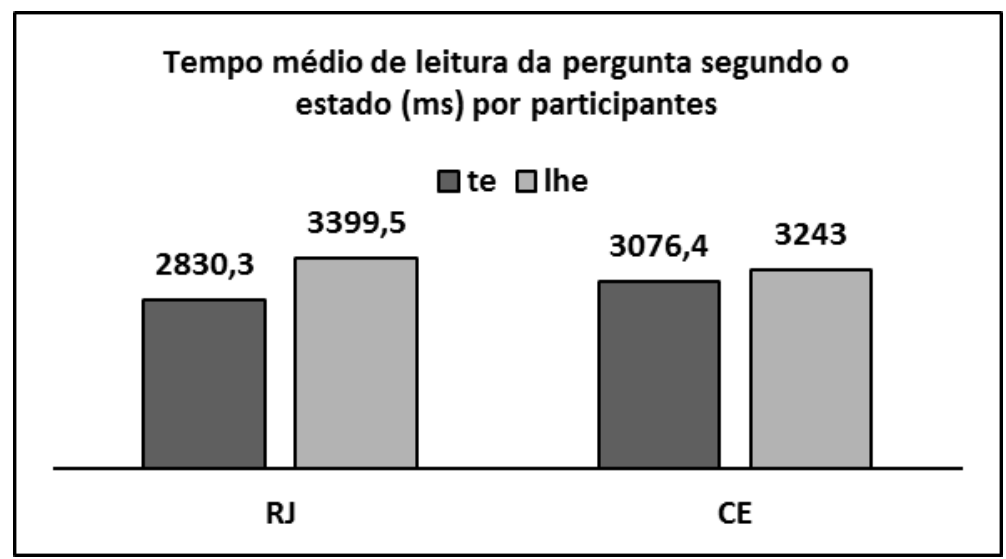

Gráfico 6: Média de tempo de leitura (ms) da pergunta interpretativa pelos participantes.

Novamente, vemos que o tempo médio de leitura das perguntas que sucediam as frases com o clítico te pelos indivíduos do RJ foi de 2830,3 milissegundos, mais baixo do que a média registrada para a leitura das perguntas que sucediam as frases com o clítico the (3399,5 milissegundos). Essa diferença também ocorreu entre as médias dos indivíduos do CE: 3076,4 milissegundos para as perguntas que sucediam as frases com te e 3242 milissegundos para as perguntas subsequentes às frases com the. $\mathrm{Na}$ verificação estatística, detectou-se diferença significativa apenas entre as médias de tempo dos participantes do RJ (t $(19)=2,69 p<0,05)$, não sendo relevante a diferença observada entre as médias dos participantes do CE ( $t$ $(19)=0,83 p=0,41)$.

\subsection{Discussão}

Os resultados do experimento de leitura automonitorada sinalizaram que os falantes fluminenses e cearenses parecem processar de modo semelhante as variantes te e Ihe em função acusativa. Ambos optaram, majoritariamente, pela leitura de 2SG para os enunciados que traziam o clítico Ihe. No entanto, os participantes das duas localidades leram mais rapidamente os estímulos experimentais que traziam o clítico te.

Com relação à variável dependente resposta da pergunta interpretativa, verificamos que as duas variantes ativaram, na maioria dos casos, a leitura de 
2SG na mente dos participantes dos dois estados. Embora os percentuais indiquem maior ativação da informação de 2SG em enunciados com te pelos sujeitos do RJ (84\%) e em enunciados com Ihe pelos sujeitos do CE (71\%), a checagem estatística da significância das diferenças registradas não nos permite falar em comportamentos distintos entre os falantes das duas variedades. Parece mais acertado considerar que tais diferenças nos percentuais se encontram dentro da faixa de aleatoriedade, previsível em testes com respostas $\mathrm{sim} /$ não.

No que diz respeito à variável tempo médio de leitura (da frase com o clítico e da pergunta interpretativa), constatamos que houve um efeito da variável tipo de clítico nas diferenças entre os tempos de leitura dos enunciados experimentais, em favor da variante te. Tanto os participantes fluminenses quanto os participantes cearenses leram mais lentamente as frases com o clítico Ihe. Essa diferença foi estatisticamente significativa em momentos diferentes da tarefa: durante a leitura das frases com os pronomes para os participantes do CE e durante a leitura das perguntas interpretativas para os participantes do RJ.

Segundo os resultados desse experimento, não é possível sustentar a hipótese segundo a qual a forma lhe é ambígua para os falantes do PB, pela possibilidade de poder se referir à 3SG. Os participantes dos dois estados efetuaram predominantemente a leitura de 2SG para esse clítico. Além disso, também não atestamos um efeito significativo da hipótese diatópica no desempenho dos participantes cearenses: estes tiveram um comportamento similar ao dos participantes fluminenses, registrando um tempo de processamento maior para efetuar a leitura dos enunciados com o clítico Ihe.

Não podemos dizer, entretanto, que a hipótese diatópica deva ser descartada. Acreditamos que outras variáveis de natureza cognitiva (ou melhor, sociocognitiva) não controladas neste experimento possam atuar no favorecimento da variante Ihe, mais frequentemente encontrada nos dialetos nordestinos. Somente após a realização de mais pesquisas experimentais sobre o tema é que poderemos alcançar um entendimento mais claro dessa questão.

\section{Considerações finais}

Neste artigo, abordamos a variação te/lhe em função acusativa, fenômeno diretamente relacionado com o processo de reestruturação do sistema de tratamento por que passa o PB desde a emergência e difusão da forma gramaticalizada você. Apesar das origens distintas dessas formas, pesquisas sincrônicas e diacrônicas a partir de corpora do PB revelam que te e Ihe atuam como variantes da expressão de 2SG na função de objeto direto em diferentes dialetos do país.

A partir dos resultados de estudos anteriores, inserimos o tema na abordagem experimental, a fim de trazer dados relativos à contraparte cognitiva da variação linguística. Dentre as hipóteses existentes acerca do tema, revisitamos, em especial, duas delas: (i) a ambiguidade referencial do clítico Ihe, que, devido às suas origens, pode se referir à $35 G$ ou à 2SG; (ii) o 
condicionamento diatópico de Ihe, que é visto como uma marca dos dialetos nordestinos.

Os resultados obtidos através do teste de leitura automonitorada, no entanto, forneceram evidências contrárias a tais hipóteses. Os participantes dos dois estados investigados (RJ e CE) efetuaram predominantemente a leitura de 2SG para os enunciados ambíguos em que havia o clítico Ihe. Além disso, os mesmos sujeitos exibiram um comportamento bastante similar quanto ao processamento das variantes analisadas, mesmo pertencendo a variedades do PB distintas quanto ao uso de Ihe.

A divergência verificada entre as hipóteses construídas a partir de corpora linguísticos e os resultados do teste experimental revela a necessidade de que mais pesquisas sejam promovidas. Longe de trazer resultados conclusivos, esperamos, com este estudo, instigar a realização de novas análises, que visem a ampliar a compreensão dos aspectos cognitivos atinentes aos fenômenos variáveis do PB e estabelecer um diálogo profícuo entre os estudos baseados no uso e no processamento linguístico.

\section{Referências bibliográficas}

Almeida, Gilce de Souza. 2009. Quem te viu quem the vê: a expressão do objeto acusativo de referência à segunda pessoa na fala de Salvador. Tese de Mestrado, Universidade Federal da Bahia. Salvador. [em linha] Disponível em: http://repositorio.ufba.br/ri/handle/ri/10995

Almeida, Gilce de Souza. 2016. Uso dos pronomes-objeto de segunda pessoa na fala de Salvador e de Santo Antônio de Jesus, Veredas, 20: 122-135.

Araújo, Francisco Jardes Nobre de e Hebe Macedo de Carvalho. 2015. TE e LHE como clíticos acusativos de $2^{a}$ pessoa em cartas pessoais cearenses, LaborHistórico, 1: 62-80.

Brito, Onilda Regina Marchioni de. 2001. "Faça o mundo te ouvir": a uniformidade de tratamento na história do português brasileiro. Tese de mestrado, Universidade Estadual de Londrina. Londrina. Inédita.

Câmara Jr., Joaquim Mattoso. 1985. História e estrutura da língua portuguesa, $4^{a}$ ed., Rio de Janeiro, Padrão.

Camargo Jr., Arnaldo Rebello. 2007. A realização do objeto direto em referência ao interlocutor. Tese de mestrado, Universidade de São Paulo. São Paulo. [em linha] Disponível em: https://teses.usp.br/teses/disponiveis/8/8142/tde-03032008-114747/ptbr.php

Faria, Ernesto. 1958. Gramática superior da língua latina, Rio de Janeiro, Livraria Acadêmica.

Garrod, Simon. 2006. Psycholinguistic research methods, em Keith Brown (ed.), Encyclopedia of Language \& Linguistics, $2^{\mathrm{a}}$ ed., Amsterdam, Elsevier Science: 251-257.

Labov, William. 1972. Sociolinguistic patterns, Philadelphia, University of Pennsylvania Press.

Labov, William. 1994. Principles of linguistic change: internal factors, Oxford, Blackwell. 
Lopes, Célia Regina, Leonardo Lennertz Marcotulio, Rachel Lucena, Thiago Laurentino de Oliveira e Camila Duarte de Souza. 2018. A reorganização do sistema pronominal de $2^{a}$ pessoa na história do português brasileiro: outras relações gramaticais, em Célia Regina Lopes (coord.), Mudança sintática das classes de palavra: perspectiva funcionalista, história do português brasileiro, Vol. 4, São Paulo, Contexto: 142-185.

Mitchell, Don. 2004. On-line methods in language processing: introduction and historical review, em Manuel Carreiras e Charles Clifton Junior (eds.), The on-line study of sentence comprehension: eyetracking, ERPs and beyond, New York, Psychology Press: 15-32.

Oliveira, Thiago Laurentino de. 2018. Língua e percepção: o processamento dos clíticos com referência ao interlocutor no português brasileiro. Tese de doutorado, Universidade Federal do Rio de Janeiro. Rio de Janeiro. [em linha] Disponível em: https://www.academia.edu/36304117/L\%C3\%8DNGUA_E_PERCEP\%C3\% 87\%C3\%830_O_Processamento_dos_cl\%C3\%ADticos_com_refer\%C3\%A Ancia_ao_interlocutor_no_Portugu\%C3\%AAs_Brasileiro

Peirce, Jonathan. 2009. Generating stimuli for neuroscience using PsychoPy. Front. Neuroinform, 2: 10.

Ramos, Conceição de Maria Araújo. 1999. O clítico de $3^{a}$ pessoa: um estudo comparativo português brasileiro/espanhol peninsular. Tese de doutorado, Universidade Federal de Alagoas. Maceió. Inédita.

Souza, Camila Duarte de. 2014. Eu te amo, eu Ihe adoro, eu quero você: a variação das formas de acusativo de $2^{a}$ pessoa em cartas pessoais (18801980). Tese de mestrado, Universidade Federal do Rio de Janeiro. Rio de Janeiro. [em linha] Disponível em: http://www. posvernaculas.letras.ufrj.br/images/Posvernaculas/3mestrado/dissertacoes/2014/3-SouzaCD.pdf

Williams, Edwin Bucher. 1994. Do latim ao português: fonologia e morfologia históricas da língua portuguesa, 6a ed., (Trad. Antônio Houaiss), Rio de Janeiro, Tempo Brasileiro.

NOTA:

O Autor é o único responsável do conteúdo e da forma deste artigo. 